\title{
ANÁLISE FILOGENÉTICA DO MINHOCUÇU RHINODRILUS ALATUS, RIGHI 1971 (GLOSSOSCOLECIDAE: ANNELIDA) BASEADA EM SEQUENCIAS DOS GENES DE rDNA 5.8S, DO ESPAÇO INTERNO TRANSCRITO (ITS1) E DA SUBUNIDADE I DA CITOCROMO C OXIDASE MITOCONDRIAL
}

\author{
Flávia de Faria Siqueira, Sávio Henrique de Cicco SAndes, Sílvia Helena \\ Costa Campos, Cleusa Graça da Fonseca, Rogério Parentoni Martins, Maria \\ Auxiliadora Drumond \& Maria Raquel Santos Carvalho \\ Instituto de Ciências Biológicas, Universidade Federal de Minas Gerais, Av. Antônio Carlos, nº 6627, \\ Pampulha, CEP 31.270-901 - Belo Horizonte, MG, Brazil, e-mail: mraquel@icb.ufmg.br
}

Siqueira, F. de F., S. H. de C. Sandes, S. H. C. Campos, C. G da Fonseca, R. P. Martins, M. A. Drumond \& M. R. S. Carvalho. 2010. Análise filogenética do minhocuçu Rhinodrilus alatus, Righi 1971 (glossoscolecidae: annelida) baseada em sequências dos genes de rDNA 5.8S, do espaço interno transcrito (its1) e da subunidade i da citocromo C oxidase mitocondrial. Acta Zoológica Mexicana (n.s.), Número Especial 2: 59-77.

RESUMO. O minhocuçu Rhinodrilus alatus Righi, 1971 é uma espécie endêmica do cerrado de Minas Gerais e tem sido explorada como isca para pesca por $>70$ anos. O objetivo do trabalho foi validar marcadores moleculares para estudos genético-populacionais, de filogenia e de filogeografia do minhocuçu. Os genes rRNA 5.8S, espaço interno transcrito (ITS1) e subunidade I da citocromo oxidase (COI) mitocondrial foram estudados. Foram amostrados indivíduos da espécie $R$. alatus $(\mathrm{n}=53)$ em diferentes hábitats de Minas Gerais e da espécie R. motucu Righi, 1971 ( $\mathrm{n}=3$ ), coletados em brejos de Goiás, no Brasil. A análise filogenética do gene do rRNA 5.8S mostrou que todas as seqüências de $R$. alatus, $R$. motucu e Eisenia fetida (Savigny, 1826) agruparam-se no mesmo clado (bootstrap $=98$ ), sugerindo que, nestes organismos, o gene é conservado. Os clados formados a partir de seqüências de rRNA 5.8S de invertebrados disponíveis na base de dados são inconsistentes do ponto de vista evolutivo, sugerindo taxas evolutivas distintas entre diferentes espécies. Para a região do ITS1, foram obtidos 11 sítios polimórficos, gerando nove haplótipos. Os exemplares de $R$. motucu apresentaram o haplótipo mais freqüente dentre os $R$. alatus de Minas Gerais, não havendo evidências moleculares de que se tratem de espécies diferentes. Para o gene COI, de um total de $634 \mathrm{pb}$, obteve-se 185 sítios polimórficos, gerando árvores filogenéticas com topologia mais adequada, separando $R$. motucu de $R$. alatus.

Palavras chave: Filogenia molecular, Rhinodrilus alatus, conservação genética.

Siqueira, F. de F., S. H. de C. Sandes, S. H. C. Campos, C. G da Fonseca, R. P. Martins, M. A. Drumond \& M. R. S. Carvalho. 2010. Análisis filogenético del minhocuçu Rhinodrilus alatus, Righi 1971 (glossoscolecidae: annelida), basada en secuencias de los genes de rDNA 5.8S, del

Recibido: 16/05/2008; aceptado: 08/01/2010. 
Siqueira et al.: Filogenia molecular do minhocuçu Rhinodrilus alatus

espacio interno transcrito (its1) y de la subunidad I de la citocromo $\mathrm{C}$ oxidasa mitocondrial. Acta

Zoológica Mexicana (n.s.), Número Especial 2: 59-77.

RESUMEN. La lombriz de tierra gigante (minhocuçu) Rhinodrilus alatus Righi, 1971 es una especie endémica del cerrado del estado de Minas Gerais y ha sido explorada como sebo para la pesca por más de 70 años. El objetivo de este trabajo fue el de validar los marcadores moleculares para estudios genético-poblacionales, de filogenia y filogeografía de este minhocuçu. Los genes rRNA 5.8S, el espaciador interno trascrito (ITS1) y la subunidad I de la citocromo oxidasa (COI) mitocondrial fueron estudiados. Se colectaron individuos de $R$. alatus $(\mathrm{n}=53)$ en diferentes hábitats del estado Minas Gerais e individuos de R. motucu Righi, 1971 ( $\mathrm{n}=3$ ) en pantanos del estado de Goiás, Brasil. El análisis filogenético del gen rRNA 5.8S mostró que todas las secuencias de R. alatus, $R$. motucu y Eisenia fetida (Savigny, 1826) se unieron en el mismo clado (bootstrap $=98$ ), sugiriendo que, en estos organismos, el gen es conservado. Los clados formados a partir de las secuencias de rRNA 5.8S de invertebrados disponibles en la base de datos son inconsistentes de punto de vista evolutivo, sugiriendo tazas de evolución distintas entre diferentes especies. Para la región del ITS1, se obtuvieron 11 sitios polimórficos, generando nueve haplotipos. Los ejemplares de $R$. motucu presentaron el haplotipo más frecuente entre los $R$. alatus de Minas Gerais, no habiendo evidencias moleculares de que sean especies diferentes. Para el gen COI, de un total de $634 \mathrm{pb}$, se obtuvieron 185 sitios polimórficos, generando árboles filogenéticos con topologia más adecuada, separando $R$. motucu de $R$. alatus.

Palabras clave: Filogenia molecular, Rhinodrilus alatus, conservación genética.

\section{INTRODUÇÃO}

O filo Annelida possui cerca de doze mil espécies descritas, com ampla distribuição nos nichos ecológicos, ocupando ambientes marinhos, de água doce e terrestres (Ruppert et al. 2005). Tradicionalmente, o filo é dividido em dois grandes grupos: os Clitellata, que compreendem minhocas (Oligochaeta) e sanguessugas (Hirundinea), e os Polychaeta, representados por vermes marinhos.

As minhocas são membros importantes da comunidade do solo, devido à sua habilidade de alterar seu habitat e criar novos nichos para outros organismos através de suas atividades. Estes organismos penetram no solo aumentando sua macroporosidade, contribuem para a transformação da matéria orgânica e a mineralização de nutrientes para as plantas. Além de mudar a diversidade e atividade microbiana no solo, as minhocas também produzem fezes ricas em nutrientes (Römbke et al. 2005).

O minhocuçu Rhinodrilus alatus Righi, 1971, da família Glossoscolecidae, é uma espécie endêmica dos cerrados da região central de Minas Gerais, Brasil, e, devido à destruição do seu hábitat e à intensa atividade extrativista foi incluído na lista das espécies ameaçadas do Estado e do Brasil (Machado et al. 2005), sob a categoria 'em perigo de extinção' (Righi 1998). O minhocuçu é extraído para uso como isca de pesca há cerca de 70 anos na região de Paraopeba (Drumond et al. 2008). Além da captura indiscriminada, sua pouca capacidade de dispersão e as práticas agrícolas também contribuem para a escassez do animal. Ainda não foi possível sua criação em cativeiro e, além disso, estes organismos não são facilmente encontrados como outras iscas (lambaris, tuviras e minhocas comuns) (Campos 2007). 
O extrativismo é considerado sócio-ambientalmente impactante sob diversos aspectos, nos quais se incluem o uso excessivo das populações de minhocuçus, o impacto do processo de extração sobre o solo e sobre várias espécies de plantas do cerrado, as pressões constantes sobre a Floresta Nacional de Paraopeba e os freqüentes conflitos entre extratores e proprietários de terras (Drumond et al. 2008). Assim, são necessárias ações de manejo e conservação da espécie, uma vez que o minhocuçu é um recurso natural ameaçado, de grande importância para a sobrevivência de milhares de pessoas, cujas populações remanescentes constituem um reservatório de material genético a ser preservado.

A filogenética molecular é uma das mais ativas áreas de pesquisa em biologia evolutiva e tem grande ligação à genética da conservação. Esta é uma ciência aplicada, que tem, entre outros, o importante objetivo de descrever a composição genética e genômica de pequenas populações ameaçadas. Usados como indicadores da história natural de uma população e de seu futuro, a genética de populações, a filogenética e a filogeografia fornecem informações fundamentais ao desenvolvimento de estratégias de manejo e conservação de espécies ameaçadas (O’Brien 1994).

Os rápidos avanços da biologia molecular têm resultado na geração de um grande número de sequências de DNA depositadas em bancos de dados públicos. Isso permite a realização de estudos comparativos de genomas ou sequências gênicas, podendose, assim, inferir dados evolutivos. A maioria dos estudos moleculares desenvolvidos em Annelida é de filogenia e se baseia no sequenciamento de genes como 5.8S, 18S, 28S, 12S, 16S rRNA (Beauchamp et al. 2001, Jamieson et al. 2002), subunidade I da citocromo oxidade (COI; Pop et al. 2003), citocromo B (Cyt B; Bleidorn et al. 2006), genes do desenvolvimento (Hox e ParaHox; Cho et al. 2004, Fröbius \& Seaver 2006) e fator de alongamento $1 \alpha$ (Kojima 1998).

Nenhum estudo com marcadores moleculares de DNA foi desenvolvido até o momento em $R$. alatus e não há sequências desta espécie disponíveis em bancos de dados públicos. A espécie de Oligochaeta mais próxima, para a qual sequências estão sendo geradas, é a minhoca de climas temperados Lumbricus rubellus Hoffmeister, 1843 com mais de 20.000 sequências produzidas (NCBI 2008). Desse modo, não se sabe ao certo se quantas espécies existem, quais as suas relações filogenéticas, como são estruturadas suas populações ou o quanto a diversidade genética já foi impactada pela extração intensiva.

Para a realização deste estudo com $R$. alatus, utilizou-se a região codificadora do gene rRNA 5.8S, o espaço interno transcrito 1 (ITS1) e a subunidade I da citocromo oxidase mitocondrial (COI). O complexo gênico de RNA ribossomal (rRNA) nuclear é uma unidade de repetições em tandem, com uma a muitas centenas de cópias (Fig. 1). Este complexo possui muitos domínios, que evoluem a taxas variadas, possuindo, assim, diferentes utilidades filogenéticas (Jorgenson \& Cluster 1988). Por outro lado, devido a seu grande conteúdo de informações, genomas mitocondriais têm sido útil em análises filogenéticas (Bleidorn et al. 2006). 
Siqueira et al.: Filogenia molecular do minhocuçu Rhinodrilus alatus

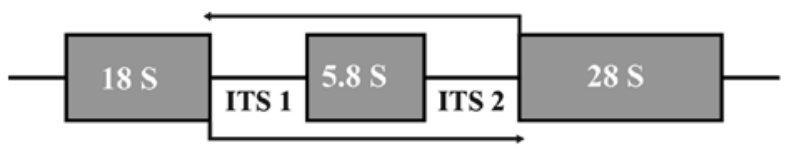

Figura 1. Esquema do complexo gênico nuclear de DNA ribossomal, que contêm os genes das subunidades do rDNA $18 \mathrm{~S}, 28 \mathrm{~S}$ e $5.8 \mathrm{~S}$, além dos espaços internos transcritos (ITS1 e ITS2). As setas indicam a posição dos iniciadores (primers) usados nas reações de PCR e a região amplificada.

Este trabalho tem como objetivo validar marcadores moleculares, como o gene 5.8S de rRNA, o ITS1 e o mtDNA COI, que permitam, através de análises filogenéticas, acompanhar ao longo do tempo o impacto da atividade extrativista e servir de ferramenta para monitoração da diversidade genética no âmbito de um projeto de manejo e uso sustentado do minhocuçu.

\section{MATERIAIS E MÉTODOS}

\section{Coleta dos indivíduos}

Indivíduos da espécie $R$. alatus $(\mathrm{N}=53)$ foram coletados em diferentes municípios e habitats (Tabela I) da região de Paraopeba, com o auxílio de extratores. No campo, foi feita a morfometria de cada indivíduo e os mesmos foram colocados em álcool $100 \%$. No laboratório, após a dissecação e retirada dos pedaços de músculo para análise genética, os espécimes foram fixados em formol 10\%. Amostras de R. motucu Righi, $1971(\mathrm{~N}=3)$, coletados em brejos de Goiás, foram também utilizados nesse estudo.

\section{Extração do DNA e amplificação de fragmentos por Reação da Cadeia de Polimerase}

Fragmentos de músculo foram dissecados e mantidos em etanol $70 \%$ a $4^{\circ} \mathrm{C}$ até o momento da extração do DNA. A extração de DNA foi feita seguindo-se o protocolo de precipitação salina descrito por Miller et al. (1988), adaptado conforme a seguinte descrição: fragmentos de tecido muscular medindo $0,4 \times 0,4 \mathrm{~cm}$ foram transferidos para tubos tipo Eppendorf, de $1,5 \mu \mathrm{L}$, ao quais se acrescentou $500 \mu \mathrm{L}$ de $\mathrm{SE}(75 \mathrm{mM}$ $\mathrm{NaCl}, 25 \mathrm{mM}$ EDTA, pH8,0) e $25 \mu \mathrm{L}$ de duodecilsulfato de sódio a $20 \%$, e $20 \mu \mathrm{L}$ de proteinase $\mathrm{K}$ a $20 \mathrm{mg} / \mathrm{mL}$. Após incubar overnight à $56^{\circ} \mathrm{C}$, adicionou-se um décimo do volume total de $\mathrm{NaCl} 5 \mathrm{M}$ e centrifugou-se durante 10 minutos a uma velocidade de 13000rpm. Em seguida, o sobrenadante foi transferido para outro tubo, onde se adicionou o dobro do volume de etanol $100 \%$ gelado. Os tubos foram colocados durante 20 minutos em freezer a $-20^{\circ} \mathrm{C}$, centrifugados durante 15 minutos a 13000 rpm e o sobrenadante foi desprezado. Lavou-se o pellet duas vezes com etanol $70 \%$ 
Tabela I. Indivíduos estudados, segundo município e hábitat, para cada marcador analisado.

\begin{tabular}{|c|c|c|c|}
\hline Município & Habitat & $5.8 \mathrm{~S} / \mathrm{ITS}$ & $\mathrm{COI}$ \\
\hline Cordisburgo & Brejo & 5 & 2 \\
\hline Morro da Garça & Cerradão & 1 & - \\
\hline Curvelo & Campo Sujo & 1 & 1 \\
\hline Papagaio & Cerrado & 3 & 1 \\
\hline Paraopeba & Braquiária & 1 & - \\
\hline Baldim & Cerradão & 1 & - \\
\hline Cordisburgo & Lagoa Drenada & 3 & 1 \\
\hline Pontinha & Cerrado & 1 & - \\
\hline Paraopeba & Cerrado & 3 & - \\
\hline Paraopeba & Cerradão & 3 & - \\
\hline Paraopeba & Eucaliptal & 2 & - \\
\hline Cordisburgo & Cerradão & 6 & 5 \\
\hline Pontinha & Eucaliptal & 2 & - \\
\hline Cordisburgo & Campo Cerrado & 2 & - \\
\hline Pompéu & Cerrado & 3 & 1 \\
\hline Curvelo & Cerradão & 2 & - \\
\hline Corinto & Veredas & 2 & - \\
\hline Corinto & Cerrado & 2 & 1 \\
\hline Andrequicé & Cerradão & 2 & - \\
\hline Três Marias & Cerrado & - & 1 \\
\hline Lassance & Cerrado & - & 1 \\
\hline Sete Lagoas & Cerrado & - & 1 \\
\hline Maravilhas & Cerradão & - & 2 \\
\hline Total & & 45 & 17 \\
\hline
\end{tabular}


gelado a $-20^{\circ} \mathrm{C}$. Uma vez desprezado o álcool $70 \%$, os tubos permaneceram à temperatura ambiente no intuito de deixar evaporar o etanol restante por 15 minutos, à temperatura ambiente, e o DNA foi ressuspendido com $300 \mu \mathrm{L}$ de TE $(10 \mathrm{mM}$ TRIS; 1 mM EDTA, $\mathrm{pH} 7,4)$.

A região do gene que codifica o rRNA 5.8S, incluindo os espaços internos transcritos ITS1 e ITS2, foi amplificada com os iniciadores (primers) descritos na literatura (Kane \& Rollinson 1994; Foward: 5' TGC TTA AGT TCA GCG GGT 3'; Reverse: 5' TAA CAA GGT TTC CGT AGG TGA A 3'). As reações de PCR foram feitas em um volume final de $50 \mu \mathrm{L}$, em $10 \mathrm{mM}$ Tris- $\mathrm{HCl} \mathrm{pH} 8,4,50 \mathrm{mM} \mathrm{KCl}, 1,5$ $\mathrm{mM} \mathrm{MgCl} 2,0,1 \%$ Triton X-100, 2,5 mM de cada dNTP, 5\% DMSO, 1 U Taq DNA polimerase e $0,3 \mu \mathrm{M}$ de cada primer, usando aproximadamente 100ng de DNA genômico como molde. O programa de amplificação foi composto por uma desnaturação inicial a $95^{\circ} \mathrm{C}$ por 5 minutos, seguida por 32 ciclos, compostos por desnaturação a $94^{\circ} \mathrm{C}$ por 45 segundos, anelamento a $60^{\circ}$ por 1 minuto e alongamento a $72^{\circ}$ por 2 minutos seguidos por um passo de alongamento final a $72^{\circ} \mathrm{C}$ por 2 minutos.

O gene da COI foi amplificado com os primers HCO2198: 5' TAA ACT TCA GGG TGA CCA AAA AAT CA 3' e LCO1490: 5' GGT CAA CAA ATC ATA AAG ATA TTG G 3' (Folmer et al. 1994), nas seguintes condições: desnaturação inicial a $94^{\circ} \mathrm{C}$ por 4 minutos, 25 ciclos com desnaturação a $94^{\circ} \mathrm{C}$ durante 1 minuto, anelamento a $50^{\circ} \mathrm{C}$ por 1 minuto e extensão a $72^{\circ} \mathrm{C}$ por 1 minuto e meio. Por fim, tem-se uma extensão final a $72^{\circ} \mathrm{C}$ por 5 minutos. A reação de PCR teve como volume final $50 \mu \mathrm{L}$, em $10 \mathrm{mM}$ Tris- $\mathrm{HCl} \mathrm{pH}$ 8,4, $50 \mathrm{mM} \mathrm{KCl}, 1,5 \mathrm{mM} \mathrm{MgCl} 2,0,1 \%$ Triton $\mathrm{X}-100,2,5 \mathrm{mM}$ de cada dNTP, $1 \mathrm{U}$ Taq DNA polimerase e $1 \mu \mathrm{M}$ de cada primer, usando aproximadamente 100ng de DNA genômico como molde. A qualidade das amplificações foi avaliada por eletroforese em gel de poliacrilamida $6 \%$, corados com nitrato de prata (Sambrook \& Russel 2001) e documentados através do scanner HP Scanjet 2200c.

\section{Purificação e sequenciamento}

Os produtos amplificados pelas PCR foram purificados com PEG 8000 para a remoção de resíduos de nucleotídeos, primers e enzima, permitindo, assim, uma reação de sequenciamento de qualidade (Sambrook \& Russel 2001).

Para cada indivíduo foram produzidas quatro sequências, sendo duas no sentido forward e duas no sentido reverse, de acordo com método de Sanger (Sambrook \& Russel 2001), em um seqüenciador MegaBace (GE Healthcare). Os primers utilizados para o sequenciamento foram os mesmos utilizados na reação PCR. Para fins de análise, a sequência foi subdividida nas regiões do ITS1 e do 5.8S, com base no alinhamento comparativo com as sequências de Eisenia fetida disponíveis no banco de dados (NCBI 2007), usando-se o software MEGA versão 4.0 (Tamura et al. 2007). 


\section{Análise dos dados}

\section{Gene rDNA 5.8S}

As sequências obtidas foram analisadas e agrupadas com programa computacional Phred-Phrap (Gordon et al. 1998), montando-se uma sequência consenso para cada indivíduo. Em seguida, todas as seqüências consenso de cada indivíduo foram alinhadas e realizou-se uma conferência visual dos picos obtidos no sequenciamento. Desta maneira, foram identificados os SNPs (single nucleotide polymorphisms) e polimorfismos do tipo inserção/deleção (indels). Foram aceitos como polimórficos apenas aqueles sítios heterozigotos em mais de uma reação de sequenciamento e localizados em regiões com qualidade de sequências alta. Os arquivos foram exportados em formato FASTA, para a análise e construção de árvores filogenéticas no programa MEGA 4.0 (Tamura et al. 2007). Do banco de dados públicos do NCBI foram obtidas seqüências de outros invertebrados (Tabela II), como Oligochaetas, Polychaetas, Hirundinida, Gastropoda e Bivalvia, para o estudo de relações filogenéticas. A árvore filogenética foi construída pelo algorítimo de Neighbor joining (Saitou \& Nei 1987), utilizando-se o método de distância-p e assumindo-se taxas evolutivas uniformes. A confiabilidade do resultado dessa topologia foi testada por bootstrap (1000 replicações) (Fig. 2).

Região do ITS1

O mesmo procedimento de análise da qualidade de seqüências adotado para o gene 5.8S rRNA foi realizado para o ITS1 e os polimorfismos encontrados foram anotados para a construção de rede haplotípica. Esta foi feita utilizando-se o software Network 4.2.0.1, por meio do método de Median-Joining (Bandelt et al. 1999) (Fig. 3).

\section{$m t D N A C O I$}

Os dados iniciais foram analisados com os mesmos softwares usados para o gene rRNA 5.8S. A história evolutiva das sequências produzidas juntamente com as dos organismos, obtidas em banco de dados do NCBI (Tabela III), foi inferida utilizando o método de Neighbor Joining (Saitou \& Nei 1987) e o teste de bootstrap foi aplicado sob a condição de 1000 replicações (Fig. 4). A análise filogenética foi conduzida pelo programa MEGA 4.0 (Tamura et al. 2007).

\section{RESULTADOS}

\section{Gene rDNA 5.8S}

Obteve-se um total de 157 pares de bases com o sequenciamento dessa região correspondendo a sequência completa deste gene. $\mathrm{Na}$ árvore filogenética construída (Fig. 2 ), formou-se um grupo monofilético com todos os indivíduos de $R$. alatus $(\mathrm{N}=45)$, 
Siqueira et al.: Filogenia molecular do minhocuçu Rhinodrilus alatus

Tabela II. Relação de espécies para as quais foram obtidas sequências no banco de dados do NCBI para a construção de árvores filogenéticas para o gene rRNA 5.8S, com os respectivos números de acesso.

\begin{tabular}{|c|c|c|c|}
\hline Espécie & Filo & Classe & Acesso no GenBank \\
\hline Eisenia fetida & Annelida & Oligochaeta & EF534709 \\
\hline $\begin{array}{l}\text { Arianta arbustorum } \\
\text { arbustorum }\end{array}$ & & & AF124053 \\
\hline Oligochaeta minima & & & AY826307 \\
\hline Oligochaeta divaricata & & & AY826306 \\
\hline Tubifex tubifex & & & AF397152 \\
\hline Ilyodrilus templetoni & & & AF360993 \\
\hline Limnodrilus hoffmeisteri & & & AF469007 \\
\hline Ctenodrilus serratus & & Polychaeta & AY100446 \\
\hline Platynereis dumerilii & & & EF117908 \\
\hline Bathykurila guaymasensis & & & DQ074765 \\
\hline Perinereis sp. Chuwei & & & AF332167 \\
\hline Perinereis floridana & & & AF332157 \\
\hline Perinereis aibuhitensis & & & AF332152 \\
\hline Proceraea cornuta & & & AF212165 \\
\hline Haemopis sanguisuga & & Hirundinida & AY425381 \\
\hline Haemadipsa cf. zeylanica & & & AY763165 \\
\hline Hirudo troctina & & & AY763164 \\
\hline Limnatis cf. nilotica & & & AY763161 \\
\hline Hirudo medicinalis & & & AY786451 \\
\hline Trocheta bykowskii & & & AF169372 \\
\hline Dina lineata dinarica & & & AF169369 \\
\hline Isabellaria isabellina isabellina & Mollusca & Gastropoda & AF254618 \\
\hline Albinaria puella puella & & & AY728370 \\
\hline Idyla bicristata & & & AF254616 \\
\hline Stagnicola catascopium & & & AF013143 \\
\hline Perna canaliculus & & Bivalvia & DQ924556 \\
\hline Perna viridis & & & DQ924555 \\
\hline Pinctada fucata & & & AB205102 \\
\hline Pinctada radiata & & & AB205095 \\
\hline Pinctada radiata & & & AB205095 \\
\hline Total & & & 29 \\
\hline
\end{tabular}


Figura 2. Árvore filogenética pelo algoritmo de NJ construída com base nas sequências de genes de rRNA 5.8S, com todos os indivíduos das espécies $R$. alatus e R. motucu estudados, além de sequências obtidas no banco de dados, referidas na Tabela III. Os valores de bootstrap se encontram próximos aos ramos.

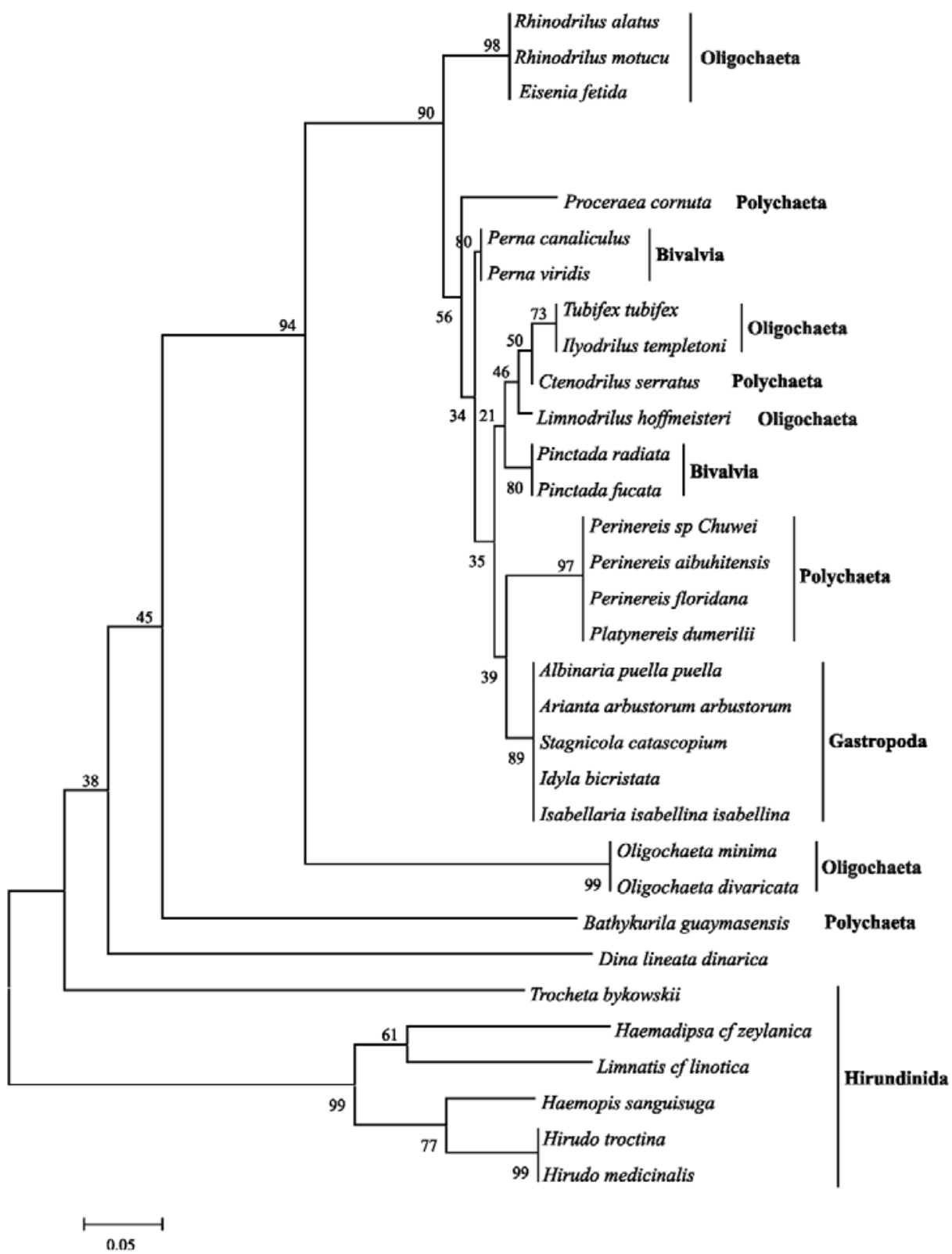


Figura 3. Rede haplotípica construída com base nas variações de sequência da região ITS1, de todos os $R$. alatus e $R$. motucu estudados. Os números sobre os ramos indicam a posição polimórfica e o tamanho dos círculos é proporcional à frequência dos haplótipos.

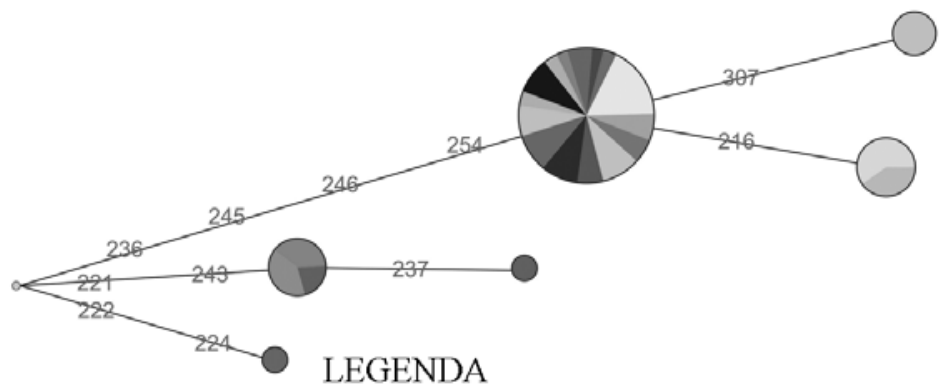

$\begin{array}{ll}\text { Papagaio/Cerrado } & \begin{array}{l}\text { Cordisburgo/Campo Cerrado } \\ \text { Andrequicé/Cerradão } \\ \text { Cordisburgo/Cerradão } \\ \text { Corinto/Veredas }\end{array} \\ \text { Morro da Garça/Cerradão } \\ \text { Corinto/Cerrado } & \begin{array}{l}\text { Curvelo/Campo Sujo } \\ \text { Cordisburgo/Brejo }\end{array} \\ \text { Paraopeba/Braquiária } \\ \text { Paraopeba/Cerrado } & \text { Baldim/Cerradão } \\ \text { Paraopeba/Cerradão } & \text { Cordisburgo/Lagoa Drenada } \\ \text { Paraopeba/Eucaliptal } & \text { Pontinha/Cerrado } \\ \text { Rhinodrilus motucu } & \text { Pompéu/Cerrado } \\ \text { Pontinha/Eucaliptal } & \text { Curvelo/Cerradão }\end{array}$

todos $R$. motucu $(\mathrm{N}=3)$ e com a $E$. fetida, suportado por um alto valor de bootstrap (=98). As sequências de $R$. alatus e $R$. motucu foram idênticas, diferindo das de $E$. fetida em apenas uma posição. Entretanto, os demais clados obtidos são inconsistentes do ponto de vista evolutivo, uma vez que as classes de Annelida e Mollusca agruparam-se desordenadamente, discordando muito das relações filogenéticas aceitas atualmente.

\section{Região do ITS1}

Na região sequenciada para $R$. alatus e $R$. motucu, com 482 pares de bases, foram identificados 11 sítios polimórficos, sendo 4 INDELs, 4 transversões e 3 transições. Com base nestas variações de sequências foram estabelecidos 9 haplótipos (Tabela IV).

A rede haplotípica construída (Fig. 3) mostra um suposto ancestral originando três grupos distintos, sendo o haplótipo mais freqüente (32 indivíduos) separado pelas posições $236,245,246$ e 254 . Este, por sua vez, se ramifica em dois subgrupos, sendo um identificado pela posição 307, englobando a população de Cordisburgo/Brejo, e o outro pela posição 216, agrupando toda população de Pompéu/Cerrado e Curvelo/Cerradão. O segundo grupo derivado do ancestral putativo difere-se pelas posi- 
Tabela III. Relação de espécies para as quais foram obtidas sequências no banco de dados do NCBI para a construção de árvores filogenéticas para o gene mtDNA COI, com os respectivos números de acesso.

\begin{tabular}{|c|c|c|}
\hline Espécie & Classe & Acesso no GenBank \\
\hline Amynthas diffringens & Oligochaeta & EF077550 \\
\hline Diplocardia invecta & & DQ257318 \\
\hline Hormogaster pretiosa & & EF653907 \\
\hline Asetocalamyzas laonicola & & EF569205 \\
\hline Eisenia fetida & & EF077596 \\
\hline Lumbricus terrestris & & DQ092908 \\
\hline Amynthas triastriatus & & EF077607 \\
\hline Metaphire schmardae & & EF077536 \\
\hline Bimastus parvus & & EF077605 \\
\hline Aporrectodea caliginosa & & EF077606 \\
\hline Drawida japonica japonica & & EF077600 \\
\hline Aglaophamus malmgreni & Polychaeta & AY996126 \\
\hline Chaetoparia nilssoni & & AY996125 \\
\hline Eteone picta & & AY996124 \\
\hline Eulalia mustela & & AY996123 \\
\hline Eumida sanguinea & & AY996121 \\
\hline Lacydonia sp. & & AY996120 \\
\hline Nereiphylla lutea & & AY996118 \\
\hline Mystides caeca & & AY996119 \\
\hline Hirudo orientalis & Hirundinida & EF405599 \\
\hline Moorebdellina biannulata & & EF405598 \\
\hline Trachelobdellina glabra & & EF405597 \\
\hline Oxytonostoma typica & & EF405596 \\
\hline Notostomum laeve & & EF405595 \\
\hline Platybdella anarrhichae & & EF405594 \\
\hline Megaliobdella szidati & & EF405593 \\
\hline Total & & 26 \\
\hline
\end{tabular}


Siqueira et al.: Filogenia molecular do minhocuçu Rhinodrilus alatus

Figura 4. Árvore filogenética pelo algoritmo de NJ construída com base nas sequências de mtDNA COI, com todos os indivíduos das espécies $R$. alatus e $R$. motucu estudados, além de sequências obtidas no banco de dados. Os valores de bootstrap se encontram próximos aos ramos.

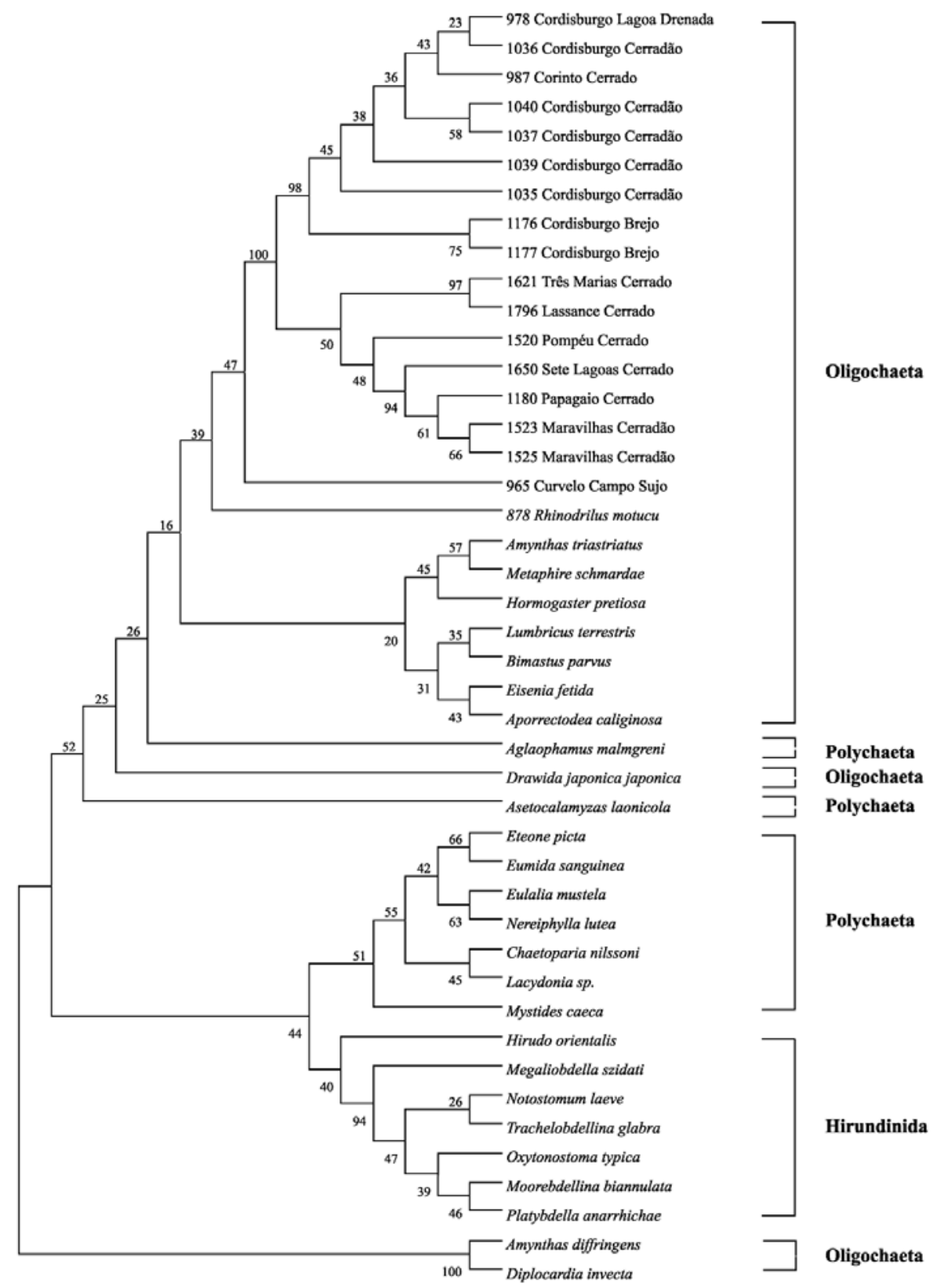




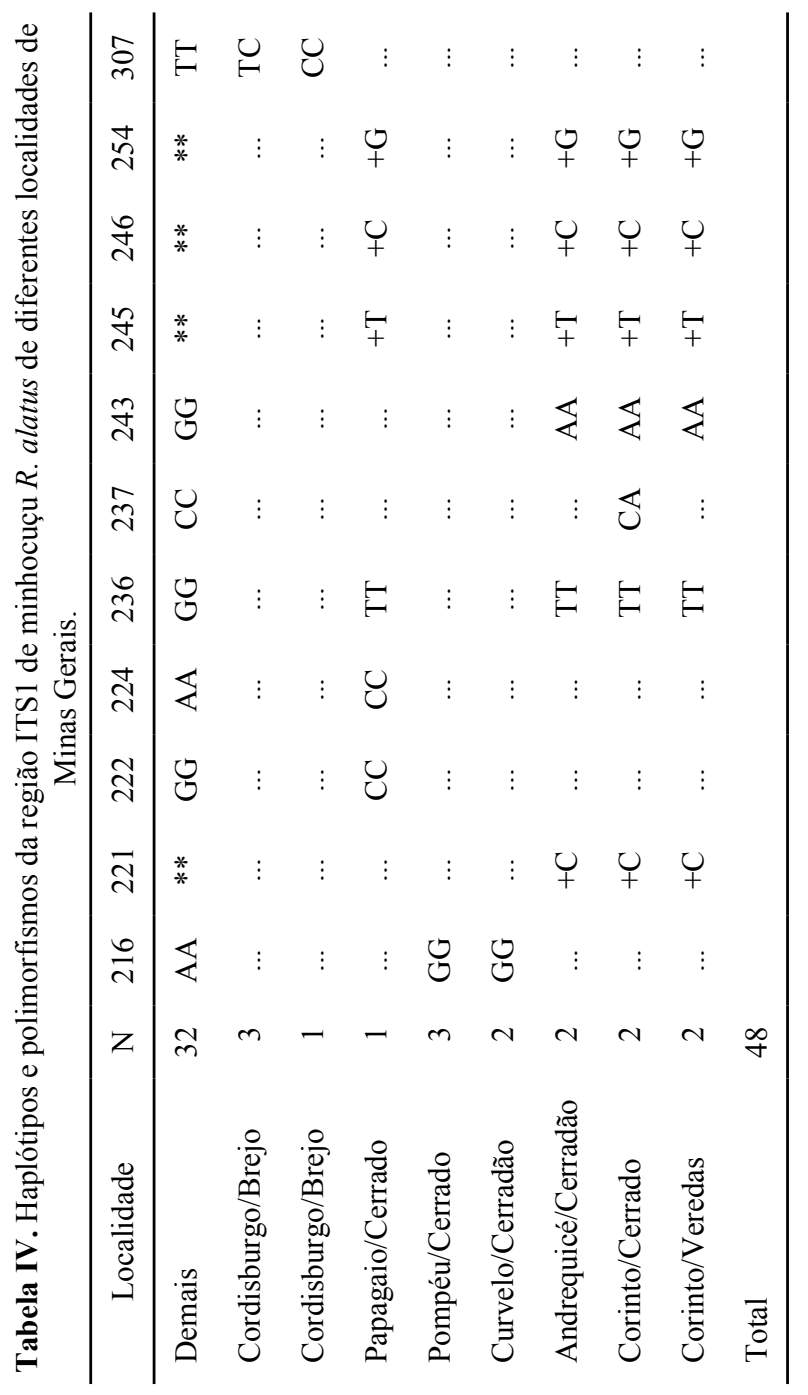


ções 221 e 243 e contém as populações de Andrequicé/Cerradão, Corinto/Veredas e Corinto/Cerrado, sendo que essa última localidade forma-se um pequeno subgrupo identificado pela divergência na posição 237. Por fim, o último grupo difere-se pelas posições 222 e 224, contendo apenas um indivíduo da população de Papagaio/Cerrado.

É importante ressaltar, que os três indivíduos da espécie $R$. motucu, coletados em Goiás, apresentam o haplótipo mais freqüente entre os $R$. alatus de Minas Gerais. Estes resultados mostram que não há, novamente, evidências moleculares de que se tratem de espécies diferentes.

\section{mtDNA COI}

O sequenciamento obtido gerou um amplicon de 634 pares de bases e um total de 185 sítios variáveis. De modo geral, a topologia da árvore filogenética (Fig. 4) mostrou se mais adequada do que a obtida em rRNA 5.8S, agrupando em clados distintos as diferentes classes de Anellida. Todos os indivíduos $R$. alatus agruparam-se em um mesmo ramo, e a espécie mais próximas a este ramo foi a $R$. motucu. É importante ressaltar que não foi possível gerar árvores com sequências de organismos de outros filos devido à grande divergência genética. Novamente, $R$. motucu mostrou-se próximo evolutivamente dos minhocuçus $R$. alatus avaliados no presente estudo.

\section{DISCUSSÃO}

Estudos recentes de sistemática molecular têm demonstrado que, em função de taxas evolutivas diferentes, certos genes (ou regiões do DNA) são mais apropriados do que outros para a reconstrução de relações evolucionárias entre táxons, em um nível particular de divergência (Simon et al.1994). Sequências de DNA não-codificante são mais variáveis do que regiões codificantes e seu uso têm se mostrado mais apropriado para discriminação de níveis taxonômicos mais próximos (Smith \& Klein 1994, Salvolainen et al. 1997). Através deste trabalho buscou-se esclarecer, baseado no sequenciamento do gene do rRNA 5.8S, do ITS1 e da mtDNA COI, as relações filogenéticas de minhocuçus distribuídos em municípios do cerrado central de Minas Gerais. A primeira etapa foi a avaliação de diferentes genes, uma vez que não há estudos moleculares sobre minhucuçus publicados ou mesmo seqüências depositadas em bases de dados.

A região codificadora do rRNA $5.8 \mathrm{~S}$ é pequena e altamente conservada e pode não permitir caracterização de espécie (Jorgenson \& Cluster 1988), embora tenha demonstrado informações relevantes para análises filogenéticas em escala basal (Hershkovitz \& Lewis 1996). Conforme os resultados obtidos, esse gene demonstrou um alto grau de conservação entre os indivíduos de $R$. alatus, $R$. motucu e E. fetida, mostrando uma evolução lenta nesse gene, mesmo em espécies de famílias distintas. 
Por outro lado, os clados formados a partir de sequências de rDNA 5.8S do banco de dados não mostraram uma topografia condizente com a taxonomia tradicional. Tal fato sugere taxas evolutivas diferentes entre diferentes espécies para esse gene, ou até mesmo artefato, já que não se pode aferir qualidade às sequências depositadas em bancos de dados públicos. Entretanto, diferentes taxas evolutivas foram descritas para o gene da subunidade 18S do complexo de rRNA (Martin et al. 2000).

Outros fatores podem contribuir para a construção de árvores filogenéticas incorretas utilizando-se dados moleculares. Dentre os problemas encontrados pode-se citar a retenção de similaridades resultante de polimorfismos conservados de um ancestral e a perda de informações devido a substituições múltiplas de um único sítio (Simon et al. 1994). Por outro lado, a análise molecular oferece a vantagem de ser uma investigação direta da constituição genotípica, permitindo a detecção da variação em nível de DNA. De acordo com a metodologia adotada, as ferramentas moleculares podem ser mais sensíveis na detecção da diversidade genética, podendo complementar os métodos clássicos baseados em caracterização morfológica (Buso 2005).

Foi usado o método de neighbor joining, que segundo Nei (1996), produz a mesma topologia das árvores construidas com o método de minimum evolution, quando o número de nucleotídeos analisados é grande $(>500)$, ou quando a quantidade de variação é grande, e se há diferenças, elas são geralmente estatisticamente não-significantes. Além disso, o autor destaca que distância $p$ ou medidas de distâncias simples como Jukes-Cantor tendem produzir topologias adequadas, até mesmo mais que medidas de distâncias sofisticadas, quando a quantidade de variações é grande, como no caso do gene da citocromo oxidase.

Os espaços internos transcritos (ITS1 e ITS2) separam os genes rDNA 18S, 5.8S e 28S. As regiões do ITS de rDNA têm mostrado evoluir rapidamente, sendo úteis em inferências filogenéticas em nível de gênero e intragênero em plantas (Baldwin 1992), em nível de espécies em peixes (Stepien et al. 1993) e em nível inter- e intraespecífico para Bivalvia (King et al. 1999). Além disso, Hershkovitz \& Lewis (1996) identificaram na região ITS uma ferramenta evolutiva a ser explorada em organismos próximos e distantes, fornecendo insights sobre a evolução de sequências de DNA em geral. A rede haplotípica obtida nesse estudo corrobora a idéia de evolução rápida dessa região, já que foram encontradas variações abundantes entre os minhocuçus analisados. O haplótipo mais freqüente está presente em vários municípios. Apenas alguns dos haplótipos mais raros aparecem em apenas uma localidade. Entretanto, em função de sua baixa freqüência, seriam necessários estudos adicionais para esclarecer se estes são realmente haplótipos privados de populações específicas.

O DNA mitocondrial tem sido um marcador molecular escolhido para reconstruir modelos históricos de demografia populacional, migrações, biogeografia e especiação (Hurst \& Jiggins 2005). Sequências nucleotídicas ou de aminoácidos, ordem dos genes mitocondriais, estrutura secundária de RNA's transportadores e desvios no 
código genético universal foram anteriormente utilizados em análises filogenéticas. Além disso, sequências únicas de genes ou a região controle mitocondrial tem comprovado ser úteis em estudos de genética de populações e de eventos de especiação (Bleidorn et al. 2006).

Dentre as vantagens do DNA mitocondrial destacam-se a facilidade em ser amplificado em diferentes táxons e, por ser haplóide, sua sequência pode ser facilmente obtida sem clonagem. Devido à sua alta taxa evolutiva o mtDNA permite resgatar o modelo de eventos históricos recentes, sem grande esforço em sequenciamento. Por último, sendo uma área com pouca recombinação, a molécula inteira pode ser assumida como tendo a mesma história genealógica (Hurst \& Jiggins 2005).

Embora o mtDNA tenha a tendência de acumular mutações mas rapidamente do que algumas regiões nucleares, o gene codificador de proteínas COI apresenta tipicamente variação específicas (Tavares \& Baker 2008). King et al. (1999) descreveram variação intraespecifica limitada em Lasmigona subviridis, mas entre as espécies deste gênero há grande diferenciação genética. As sequências produzidas para este gene entre os minhocuçus, mostraram abundante variação intra e interespecífica.

Outro aspecto questionado por esse estudo é se realmente todos os indivíduos coletados no cerrado central de Minas Gerais são da espécie $R$. alatus, já que a literatura descreve uma distribuição mais restrita (Drumond et al. 2007). Nesse contexto, a análise filogenética pode elucidar o status de um táxon e ajudar a alcançar o objetivo de proteger entidades distintas geneticamente e evolutivamente, podendo também mostrar as reais prioridades para alocação de esforços (Andreasen 2005). O manejo efetivo de espécies em risco pode ser complicado devido à inexistência de informação taxonômica adequada da espécie (King et al. 1999). Técnicas moleculares (primariamente, sequenciamento de DNA) têm transformado a habilidade dos cientistas de descrever e definir a diversidade biológica, sendo, aliadas a outros tipos de dados, ferramentas fundamentais para descrição de espécies crípticas. Espécies crípticas requerem uma atenção especial no planejamento de conservação devido a dois problemas: espécies já consideradas extintas ou ameaçadas podem ser compostas de múltiplas espécies, que são até mesmo mais raras do que previamente suposto; e, diferentes espécies podem requerer diferentes estratégias de conservação (Blickford et al. 2006). No presente estudo, o sequenciamento do gene rDNA 5.8S não auxiliou na separação das espécies estudadas ( $R$. alatus e $R$. motucu), pois não mostrou nenhuma variação. Já o ITS1, em função da abundante variação intraespecífica, mostrou-se útil na separação de algumas subpopulações. Entretanto, o ITS1 também não foi capaz de separar as espécies estudadas (R. alatus e $R$. motucu), uma vez que $R$. motucu apresenta o haplótipo mais comum presente em $R$. alatus.

Uma profunda compreensão das relações filogenéticas de $R$. alatus é essencial para prover informações necessárias para o acesso do status de espécie e para o planejamento, implantação e monitoramento de programas de manejo e uso sustentável. 
De acordo com os resultados obtidos nessa fase do estudo, faz-se necessário investigar outros genes, como o ITS2 e os rDNA $18 \mathrm{~S}$ e rDNA $28 \mathrm{~S}$, para melhor esclarecimento das relações filogenéticas do minhocuçu, bem como para avaliar o quanto a espécie foi impactada pela atividade extrativista exacerbada. Estudos futuros também incluirão a investigação de correlação entre distribuição geográfica $v s$. haplótipos, e haplótipos vs. variações morfológicas, que estão sendo coletadas para esses animais (comprimento, diâmetro do animal, diâmetro da galeria).

Em conclusão, o gene do rDNA $5.8 \mathrm{~S}$ se mostrou conservado, não tendo sido observadas variações entre os indivíduos testados de $R$. alatus e $R$. motucu. Essa sequência foi a mesma encontrada nas bases de dados para $E$. fetida, sugerindo uma forte conservação entre estas espécies. A região ITS1 mostrou-se polimórfica em $R$. alatus, podendo ser utilizada, associada a outros marcadores moleculares, em estudos de Genética de Populações, aplicando-se a conservação e uso sustentável da espécie. O gene mtDNA pode conter informações filogenéticas relevantes, sendo também fundamental, associado aos outros genes nucleares, para estudos de filogenia e genéticopopulacionais.

\section{AGRADECIMENTOS}

À Fundação de Amparo à Pesquisa de Minas Gerais (FAPEMIG), ao Conselho Nacional de Desenvolvimento Científico e Tecnológico (CNPq) e à Conservação Internacional do Brasil, pelo suporte financeiro concedido.

\section{LITERATURA CITADA}

Andreasen, K. 2005. Implications of molecular systematic analyses on the convervation of rare and threatened taxa: contrasting examples from Malvaceae. Conservation Genetics. 6: 399-412.

Baldwin, B. G. 1992. Phylogenetic utility of the internal transcribed spacers of ribosomal DNA in plants: an example from the Compositae. Molecular Phylogenetics and Evolution. 1: 3-16.

Bandelt, H. J., P. Forster \& A. Röhlmo. 1999. Median-joining networks for inferring intraspecific phylogenies. Molecular Biology and Evolution. 16(1): 37-48.

Beauchamp, K. A., R. D. Kathman, T. S. McDowell \& R. P. Hedrick. 2001. Molecular phylogeny of the tubificid oligochaetes with special emphasis on Tubifex tubifex (Tubificidae). Molecular Phylogenetics and Evolution. 19(2): 216-224.

Bleidorn, C., L. Podsiadlowsky \& T. Bartolomaeus. 2006. The complete mitochondrial genome of the orbiniid polychate Orbinia latreillii (Annelida: Orbiniidae) - A novel gene order for Annelida and implications for annelid phylogeny. Gene. 370: 96-103.

Blickford, D., D. J. Lohman, N. S. Sodhi, P. K. L. Ng, R. Meier, K. Winker, K. K. Ingram \& I Das. 2006. Cryptic speciess as a window on diversity and conservation. Trends in Ecology and Evolution. 22(3): 148-155.

Buso, G. S. C. 2005. Marcadores moleculares e análise filogenética. Embrapa Recursos Genéticos e Biotecnologia, Série Documentos No. 136. CENARGEN, Brasília.

Campos, V. M. C. 2007. Criação de minhocuçu. Fundação Centro Tecnológico de Minas Gerais. CETEC. http://www.sbrt.ibict.br. 
Siqueira et al.: Filogenia molecular do minhocuçu Rhinodrilus alatus

Cho, P. Y., S. J. Cho, M. S. Lee, J. A. Lee, E. S. Tak, C. Shin, J. K. Choo, S. C. Park, K. S. Lee, H. Y. Park \& C. B. Kim. 2004. A PCR-Based analysis of Hox genes in an earthworm, Eisenia andrei (Annelida: Oligochaeta). Biochemical Genetics. 42(5/6): 209-216.

Drumond, M. A., S. H. C. Campos, A. Q. Guimarães, R. P. Martins, L. C. Giovanetti \& M. Matteuzo. 2007. Distribuição geográfica do minhocuçu Rhinodrilus alatus, Righi 1971 e sua contribuição para a revisão do status de conservação da espécie. In: VIII Congresso de ecologia do Brasil. São Paulo, 2007, Anais. Caxambu, MG: Sociedade de Ecologia do Brasil.

Drumond, M. A., S. H. C. Campos, A. Q. Guimarães \& J. T. Nunes. 2008. Uso e conservação do minhocuçu Rhinodrilus alatus. MG Biota. 1: 5-23.

Folmer, O., M. Black, W. Hoeh, R. Lutz \& R. Vrijenhoek. 1994. DNA primers for amplification of mitochondrial cytochrome c oxidase subunit I from diverse metazoan invertebrates. Molecular Marine Biology and Biotechnology. 3: 294-299.

Fröbius, A. C. \& E. C. Seaver. 2006. ParaHox gene expression in the polychaete annelid Capitella sp. I. Development Genes and Evolution. 216: 81-88.

Gordon, D., C. Abajian \& P. Green. 1998. Consed: a graphical tool for sequence finishing. Genome Research. 8 (3): 195-202.

Hershkovitz, M. A. \& L. A. Lewis. 1996. Deep-level diagnostic value of the rDNA-ITS region. Molecular Biology and Evolution. 13(9): 1276-1295.

Hurst, G. D. D. \& F. M. Jiggins. 2005. Problems with mitochondrial DNA as a marker in population, phylogeographic and phylogenetic studies: the effects of inherited symbionts. Proceedings of the Royal Society B: Biological Scienses. 272(1572): 1525-1534.

Jamieson, B. G. M., S. Tillier, A. Tillier, J. L. Justine, E. Ling, S. James, K. McDonald \& A. F. Hugall. 2002. Phylogeny of the Megascolecidae and Crassiclitellata (Annelida: Oligochaeta): combined versus partitioned analysis using nuclear (28S) and mitochondrial (12S, 16S) rDNA. Zoosystema. 24(4): 707-734.

Jorgensen, R. \& P. Cluster. 1988. Modes and tempos in the evolution of nuclear ribosomal DNA: new characters for evolutionary studies and new markers for genetic and population studies. Annals of the Missouri Botanical Garden. 75: 1238-1247.

Kane, R. A. \& D. Rollinson. 1994. Repetitive sequences in the ribosomal DNA internal transcribed spacer of Schistosoma haematobium, Schistosoma intercalatum and Schistosoma mattheei. Molecular and Biochemical Parasitology. 63: 153-156.

King, T. L., M. S. Eackles, B. Gjetvaj \& W. R. Hoeh. 1999. Intraspecific phylogeography of Lasmigona subviridis (Bivalvia: Unionidae): conservation implications of range discontinuity. Molecular Ecology. 8:65-78.

Kojima, S. 1998. Paraphyletic status of Polychaeta suggested by phylogenetic analysis based on the amino acid sequences of Elongation Factor-1 $\alpha$. Molecular Phylogenetics and Evolution. 9(2): 255261.

Machado, A. B., C. S. Martins \& G. M. Drummond. 2005. Lista da Fauna Brasileira Ameaçada de Extinção. Fundação Biodiversitas, Belo Horizonte.

Martin, P., I. Kaygorodova, D. Y. Sherbakov \& E. Verheyen. 2000. Rapidly evolving lineages impede the resolution of phylogenetic relationships among Clitellata (Anellida). Molecular Phylogenetics and Evolution. 15(3): 355-368.

Miller, A.S., D. D. Dykes \& H. F. Poleski. 1988. A simple salting out procedure for extracting DNA from human cells. Nucleic Acids Research. 16: 1215.

Nei, M. 1996. Phylogenetic analysis in molecular evolutionary genetics. Annual Reviews in Genetics. 30: 371-403.

NCBI. 2008. National Center for Biotechnology Information. United States of America. www.ncbi.nlm. nih.gov. 
O'Brien, S. J. 1994. A role for molecular genetics in biological conservation. Proceedings of the National Academy of Sciences of the United States of America. 91: 5748-5755.

Pop, A. A., M. Wink \& V. V. Pop. 2003. Use of 18S, 16S rDNA and cytochrome c oxidase sequences in earthworm taxonomy (Oligochaeta, Lumbricidae). Pedobiologia. 47: 1-6.

Righi, G. 1971. Sobre a família Glossoscolecidae (Oligochaeta) no Brasil. Arquivos de Zoologia. 20(1): 1-95.

Righi, G. 1998. Oligoquetas. Pp. 571-583. In: A.B.M. Machado, G.A.B. da Fonseca, R.B. Machado, L.M. de S. Aguiar and L.V. Lins (Eds.). Livro vermelho das espécies ameaçadas de extinção da fauna de Minas Gerais. Fundação Biodiversitas. Belo Horizonte.

Römbke, J., S. Jänsch \& W. Didden. 2005. The use of earthworms in ecological soil classification and assessment concepts. Ecotoxicology and Environmental Safety. 62: 249-265.

Rupert, E. E., R. S. Fox \& R. D. Barnes. 2005. Zoologia dos Invertebrados. $7^{\text {a }}$ ed. Roca, São Paulo.

Saitou, N. \& M. Nei. 1987. The neighbor joining method: a new method for reconstructing phylogenetic trees. Molecular Biology and Evolution. 4: 406-25.

Salvolainen, V., R. Spichiger \& J. F. Manen. 1997. Polyphyletism of Celestrales deduced from a chloroplast noncoding DNA region. Molecular Phylogenetics and Evolution. 7: 145-157.

Sambrook, J. \& D. W. Russel. 2001. Molecular cloning: a laboratory manual. $3^{\text {a }}$ ed. Cold Spring Harbor Laboratory, New York.

Simon, C., F. Frati, A. Beckenbach, B. Crespi, H. Liu \& P. Flook. 1994. Evolution, weighting, and phylogentic utility of mitochondrial gene sequences and a compilation of conserved Polymerase Chain Reaction primers. Annals of the Entomological Society of America. 87(6): 651-700.

Smith, D. \& A. S. Klein. 1994. Phylogenetic inferences on the relationships of North American and European Picea species based on nuclear ribosomal 18S sequences and the internal transcribed spacer region. Molecular Phylogenetics and Evolution. 3: 17-26.

Stepien, C. A., M. T. Dixon \& D. M. Hillis. 1993. Evolutionary relationships of the blennioid fish families Clinidae, Labrisomidae, and Chaenopsidae: congruence between DNA sequence and allozyme data. Bulletin of Marine Science. 52: 496-515.

Tamura, K., J. Dudley, M. Nei \& S. Kumar. 2007. MEGA4: Molecular Evolutionary Genetics Analysis (MEGA) Software Version 4.0. Molecular Biology and Evolution. 24: 1596-1599.

Tavares, E. S. \& A. J. Baker. 2008. Single mitochondrial gene barcodes reliably identify sister-species in diverse clades of birds. BMC Evolutionary Biology. 8: 81-95. 